\title{
МЕТАИНДИВИДУАЛЬНАЯ МОДЕЛЬ ДЕСТРУКТИВНОСТИ. СООБЩЕНИЕ 2
}

\author{
Л.Я. ДОРФМАН ${ }^{\mathrm{a}}$ К.В. ЗЛОКАЗОВ \\ ${ }^{2}$ Пермский государственный институт культуры, 614000, Россия, Пермь, ул. Газеты Звезда, д. 18 \\ ${ }^{5}$ Уральский юридический институт, 620137, Россия, Екатеринбург, ул. Комсомольская, д. 21
}

\begin{abstract}
Резюме
Предлагается метаиндивидуальная модель деструктивности в русле концепции метаиндивидуального мира. Данная модель призвана преодолеть разрозненные представления о деструкции и представить общий взгляд на нее. Вводится общее понимание деструктивности как самостоятельного феномена, несводимого к агрессии, депрессии, травме, оскорблениям или другим негативным явлениям. Общий взгляд на деструктивность раскрывается в понятии негативного деструктивного мира у психически здоровых людей. Он возникает в результате деформаций метаиндивидуального мира - как в целом, так и на уровне его отдельных систем и доменов. В негативном деструктивном мире выделяются четыре домена: недовольство собой, стремление к власти над людьми, неприятие людей, обособление от людей. Предположительно доменная организация негативного деструктивного мира приводит к его гетерогенности. Вводится монохромная метафора «белый (светлый) - черный (темный)» как маркер метаиндивидуального мира («светлый») и негативного деструктивного мира («темный»), а также полярных отношений и континуальных переходов между ними. Монохромная метафора ограничивается сенсорно-перцептивным уровнем и отвечает операциональным требованиям маркера: обладать континуальностью, ассоциироваться с показателями континуальных переходов от метаиндивидуального мира к негативному деструктивному миру, иметь внешний и критериальный характер по отношению к мирам, быть простьм, доступным наблюдению и измерениям.
\end{abstract}

Ключевые слова: деструктивность, метаиндивидуальная модель, деформации, негативный деструктивный мир, домены, монохромная метафора.

\section{Введение}

В предыдущей статье (Дорфман, Злоказов, 2017) была выдвинута идея о гетерогенной природе деструктивности. Эта идея основывалась на том, что существует некото- рое множество частных форм деструктивности и выделяются разрозненные теоретические представления о них. Вместе с тем предполагалось, что частные формы деструктивности имеют общий корень и для его выявления необходима соответ- 
ствующая концепция, которая позволила бы свести частные формы деструктивности к единой основе. В связи с этим была предпринята попытка наметить перспективу изучения деструктивности с позиций интегративного подхода.

В настоящей статье данный подход получает развитие, намечаются теоретико-эмпирические контуры метаиндивидуальной модели деструктивности с позиций концепции метаиндивидуального мира (Дорфман, 2016; Dorfman, Barashkova, 2016). Данная модель преодолевает в определенной степени разрозненные представления о деструктивности и подводит под них общие основания.

Предлагается ввести в научный оборот понятие негативного деструктивного мира у психически здоровых людей. Оно призвано собрать воедино значительную часть негативности и деструкции личности в отношении себя, ее отношений и взаимодействий с людьми и объектами своего мира. Негативный деструктивный мир понимается как негативно-деструктивная альтернатива позитивно-конструктивным особенностям метаиндивидуального мира по линии деструктивности (негативности) - конструктивности (позитивности). Соответственно выделяются домены негативного деструктивного мира как альтернативы доменам метаиндивидуального мира. Предлагается изучать негативный деструктивный мир по двум дополняющим линиям. В соответствии с первой принимаются во внимание деформации метаиндивидуального мира и рассматриваются их постепенные переходы к негативному деструктив- ному миру. Согласно второй линии учитывается возникающий при этом негативный деструктивный мир, который (в пределе) противостоит метаиндивидуальному миру.

Ставится фундаментальный вопрос поиска маркера континуальных переходов от метаиндивидуального мира без деформаций к метаиндивидуальному миру с деформациями и далее к негативному деструктивному миру. Это также вопрос операционализации маркера в определенных аспектах. Приводятся аргументы в пользу сенсорно-перцептивной (монохромной) метафоры в качестве возможного маркера метаиндивидуального мира и негативного деструктивного мира.

Все эти проблемные вопросы ставятся и подвергаются анализу в настоящей статье.

\section{Метаиндивидуальный мир (МИМ)}

Онтологически МИМ представляет собой индивидуальность (личность) и ее включение в более широкие, чем она сама, системы, т.е. собственно индивидуальность (личность) и ее выход за собственные пределы, представленность за границами своего тела (экстракорпорально) в ближнем социальном окружении. Этот взгляд на индивидуальность тесно перекликается с идеей В.А. Петровского (Петровский, 1981, 2009, 2013; Петровский, Старовойтенко, 2012) о личности как мультисубъектной общности, содержащей в себе интраиндивидные, интериндивидные и метаиндивидные ипостаси человека.

В свете недавнего обновления концепции МИМ (Дорфман, 2016; 
Dorfman, Barashkova, 2016) кратко изложим ее современные ключевые положения как методолого-теоретическое основание исследования деструктивности.

1. Опираясь на полисистемный подход, концепция МИМ представляет собой версию плюралистических теорий, связанных с поисками оснований, приводящих к определению нескольких систем и их сосуществования, многокачественности явлений, вызванных разнородными потоками детерминации. На психические явления в МИМ влияют, прежде всего, внутренние и внешние источники детерминации.

2. В МИМ одну систему его качеств инициирует внутренняя детерминация (система 1), другую систему его качеств - внешняя детерминация (система 2). В упрощенном виде система 1 объединяет личность и ее ближнее окружение. Ядром системы 1 является личность (системообразующий фактор), а периферией ближнее окружение (подсистема). Система 2 тоже объединяет личность и ее ближнее окружение, но иначе, чем в системе 1. Ядром системы 2 является ближнее окружение (системообразующий фактор), периферией - личность (подсистема).

3. Каузально (и функционально) системы 1 и 2 разворачиваются в противоположных направлениях и выполняют разные функции. Кроме того, в структурном плане личность и ее ближнее окружение включаются в системы 1 и 2 разными сторонами, поэтому личность и ее ближнее окружение расходятся по системам 1 и 2, не смешиваясь.

4. МИМ имеет четырехмерную основу, что приводит к выделению в нем четырех относительно самостоятельных качественных узлов, или доменов.

Первым является домен авторства (ядро системы 1). Личность воспринимает себя причиной поступков, которые она совершает, и результатов, к которым она приходит (самопричинение) (см. также: Петровский, 1997).

Вторым является домен психологического обладания (периферия системы 1). Личность устремлена на владение кем-либо или чем-либо как своей собственностью. В результате ближнее окружение (или его отдельные члены) становится «моим», оно - «мое» (см. также: Pierce et al., 2003).

Третий домен обозначается как принятие (ядро системы 2). Личность принимает членов ближнего окружения такими, какие они есть и как они себя ведут. Ситуации, состояния или предметы оцениваются личностью глазами близких людей - воспринимающих, познающих, относящихся, принимающих их намерения и цели (см. также: Echterhoff et al., 2009).

Четвертый домен обозначается как связанность (периферия системы 2). Личность тяготеет к людям, устанавливает отношения и объединяется с ними. Связанность понимается как «часть социума», «чувство принадлежности», «привязанность». Связанность подразумевает также «близость», «присоединение», «кооперацию», «зависимость» (см.: Blatt, 2008).

Таким образом, в МИМ домены авторства и обладания совместно характеризуют систему 1, а домены принятия и связанности - совместно 
систему 2. При этом область личности распадается на домены авторства и связанности, область ближнего окружения - на домены обладания и принятия. Имеются эмпирические свидетельства, поддерживающие теоретические представления о четырехмерном устройстве МИМ (Дорфман, Зубакин, 2008; Dorfman, Ogorodnikova, 2007).

\section{Негативный деструктивный мир}

Мы предлагаем ввести в научный оборот понятие негативного деструктивного мира у психически здоровых людей. Это понятие призвано собрать воедино значительную часть негативности и деструкции личности в отношении себя, ее отношений и взаимодействий с людьми и объектами своего мира.

В отличие от деструктивности, которой было уделено много места выше, понятие негативности подразумевалось, но оставалось в тени. Между тем добавленная характеристика негативности имеет смысл в нескольких планах. Дело в том, что деструкция может быть и позитивной, проявляясь, например, в боевых действиях против врага, полицейских операциях против преступников и в освобождении заложников или в спортивных единоборствах. Речь идет, однако, именно о негативной деструктивности. С другой стороны, негативность касается не только деструктивности. Неоднократно отмечаемые выше смежные с деструктивностью явления по преимуществу также несут на себе печать негативности. Вместе с тем имеется в виду только та порция негативного заряда, которая приво- дит к деструкции. Понятием негативности обозначаются не столько отрицательные эмоции, сколько более общее явление - негативное, враждебное отношение, неприятие или обесценивание. Оно касается самой личности, окружающих ее людей, объектов внешнего мира. Отсюда принципиальная готовность личности изменять, подвергать трансформации и деформации, разрушать, уничтожать, даже если на пути этой готовности возникают барьеры и реализация этой готовности невозможна, вызывая (в пределе) бессилие. Это своеобразный способ субъективного оправдания негативного отношения, с одной стороны, попытка устранить (вытеснить) негативный фактор, освободиться от него, с другой (ср.: Baumeister, 1990; Baumeister, Scher, 1988).

По контрасту отметим, что МИМ, скорее всего, носит позитивный конструктивный (созидающий) характер. В определенном смысле негативный деструктивный мир (НДМ) противостоит и служит антиподом МИМ. В то же время не исключены переходы от МИМ к НДМ. Так возникает вопрос изменений и деформаций МИМ.

НДМ как форма деформаиии МИМ. Как отмечалось выше, в МИМ ядром системы 1 является личность (системообразуюший фактор), а периферией - ближнее окружение (подсистема). Система 2 тоже объединяет личность и ее ближнее окружение, но иначе, чем в системе 1. Ядром системы 2 является ближнее окружение (системообразующий фактор), периферией - личность (подсистема). 
Если личность управляет ближним окружением в системе 1 (в МИМ), значит, ее ядро и периферия предрасположены к переменам. Правда, у ядра должна быть большая устойчивость, а у периферии бо́льшая подвижность. Но это уже детали о степенях изменчивости (или стабильности) компонентов системы 1. Когда члены ближнего окружения управляют личностью в системе 2 (в МИМ), это значит, что ее ядро и периферия тоже предрасположены к переменам, опять-таки пусть даже у ядра бо́лшая устойчивость, а у периферии бо́льшая подвижность. Кроме того, можно полагать, что системы 1 и 2 производят какие-то изменения друг в друге. В общем подвижность и гибкость являются ключевыми характеристиками МИМ. Не углубляясь в анализ изменений, просто отметим, что могут быть обшие и частные перемены в МИМ. Общие перемены возникағот в обеих системах МИМ, затрагивая их все домены, а частные перемены - в отдельных системах. Перемены в отдельных доменах также относятся к разряду частных, причем они возникают под влиянием «своих» и, видимо, «чужих» систем.

Далее отметим некоторое множество возможных форм изменений МИМ. В первом приближении их можно разделить на благоприятные (позитивные) и неблагоприятные (негативные). Благоприятными являются, скажем, метаиндивидуальные формы креативности (Дорфман, 2007) и дисциплинированности (Дорфман, Лядов, 2015). Неблагоприятны изменения МИМ, приводящие его к деформациям (о деформациях см.: Сыманюк, 2005), в нашем случае - к НДМ. Общие деформации приводят к негативным деструктивным изменениям МИМ в целом, носят неспецифический, неизбирательный характер. НДМ возникает как своеобразный итог таких перемен. Частные деформации, наоборот, свидетельствуют о деформациях МИМ неполно, изб́ирательно, в его отдельных системах и доменах.

В системе 2 (МИМ) отдельные члены ближнего окружения могут вызывать деструкцию у личности. В системе 1 (МИМ), наоборот, личность может вызывать деструкцию у членов своего ближнего окружения. Кроме того, личность может направлять деструкцию на себя. К примеру, личность наказывает себя от имени членов ближнего окружения (путем их интроекции в сознание в рамках системы 2) или устраняет нежелательные стороны своего Я (через деструкцию членов ближнего окружения в рамках системы 1). Самодеструкцию, следовательно, можно рассматривать в трех контекстах: систем 2 и 1, а также их взаимодействий. Деструкция личностью членов ближнего окружения тоже просматривается в трех контекстах: систем 2 и 1, а также их взаимодействий. При этом важной становится ось «Я - Другой».

Но как возникает неблагоприятный НДМ, если его предпосылкой служит благоприятный MИМ? Очевидно, что деформации могут быть следствием нарушения «нормального» хода межличностных отношений, и причин тому может быть неисчислимое множество. Обратим внимание на устойчивость (и резистентность) - чувствительность (и ранимость) МИМ к угрозам 
и воздействиям на способ его существования. В предыдущей работе (обзор: Дорфман, Злоказов, 2016) мы указывали на самоуважение, угрозу самомнению, заслуженное самонаказание, выпадение из социальных связей как факторы деструкции. С другой стороны, возникает тема атак на МИМ в дифференциально-структурном плане. Это вопрос деструктивных последствий для отдельных доменов МИМ.

НДМ расширяет понимание деструктивности в общем и по линиям его доменов, причем не обращаясь к агрессии, травме, депрессии или другим родственным явлениям. Рассмотрим вопрос состава НДМ, его качественных узлов, т.е. доменов.

Если МИМ может подвергаться деформациям и из него «вырастает» НДМ, не исключено, что его доменное строение подобно доменам МИМ. Но следует ожидать, что у доменов НДМ будет собственное содержание. Формально-логически это значит, во-первых, что через домены МИМ (авторства, обладания, принятия и связанности) проходят деформации МИМ, разнородные и разные. Во-вторых, деформации МИМ могут возникать через одни домены и не возникать через другие. Наиболее полным будет случай деформации всех четырех доменов МИМ. В-третьих, домены НДМ имеют относительно высокие степень обобщения и уровень абстракции. Один и тот же домен НДМ может соотноситься с несколькими уже известными частными формами деструктивности. Родство одних частных форм деструктивности с другими будет определяться их принадлежностью одному домену, а их различия - принадлежностью разным доменам. НДМ дифференцирует формы деструкции по новому, доменному основанию.

Специальной является задача поиска критериев для содержательных переходов от доменов МИМ к доменам НДМ. По сути, это задача на операционализацию доменов НДМ. Наиболее внятное, экономное и простое решение состоит в том, чтобы обозначить НДМ как негативно-деструктивную альтернативу позитивно-конструктивным особенностям МИМ, включая их сравнения по доменному критерию.

Предлагается следующее определение доменов НДМ. Центральной характеристикой домена авторства (МИМ) является самость. Его негативно-деструктивной альтернативой (НДМ) служит недовольство собой. Область Я сохраняется в НДМ, но в альтернативном, негативно-деструктивном варианте. Ключевыми признаками домена «Недовольство собой» выступают негативное самоотношение, пониженное самоуважение, пессимизм. Предположительно сопоставимыми формами и факторами деструкции, описанными в литературе, являются следующие: пониженное самоуважение, желание принести себе вред и ущерб, неприятие себя (Baumeister, Scher, 1988), негативное мнение о себе (Lundh et al., 2007; Renaud, McConnell, 2007). К ним можно отнести также заслуженное самонаказание (Callan et al., 2014), ментальное поражение, утрату самоидентичности (Ehlers et al., 1998, 2000), бессилие (Frederick, 1986; Herman, 1992), склонность личности испытывать неприязнь и быть придирчивой к себе, бояться 
успеха и счастья (Hyler, Rieder, 1987).

Центральной характеристикой домена психологического обладания (МИМ) являются позитивные воздействия на людей. Его негативнодеструктивной альтернативой (НДМ) служит стремление $\kappa$ власти над людьми. Область обладания сохраняется в НДМ, но в альтернативном, негативно-деструктивном варианте. Ключевыми признаками домена «Власть над людьми» выступают стремление к превосходству, вмешательство, давление. Предположительно сопоставимыми формами и факторами деструкции, описанными в литературе, являются следующие: оскорбление (Muller et al., 2000; Taussig, Litrownik, 1997), негативное лидерство (Krasikova et al., 2013; Reed, Bullis, 2009; Thoroughgood et al., 2012), тирания (Ashforth, 1994), деструктивные фантазии, в том числе имеющие креативный характер (Knauss, 1999; Minocha et al., 2014).

Центральной характеристикой домена принятия (МИМ) является принятие членов ближнего окружения такими, какие они есть и как они себя ведут. Негативно-деструктивной альтернативой (НДМ) служит их неприятие. Область «Другого» сохраняется в НДМ, но в альтернативном, негативно-деструктивном варианте. Ключевыми признаками домена «Неприятие людей» выступают категоричность, повышенная критичность, нетерпимость. Предположительно сопоставимыми формами и факторами деструкции, описанными в литературе, являются следуюшие: тшеславие, высокомерие, нарциссизм (Baumeister, 1997; Miller et al., 2009; Vazire, Funder, 2006).
Центральной характеристикой домена связанности (МИМ) является тяготение к членам ближнего окружения. Негативно-деструктивной альтернативой (НДМ) служит обособление от них. Область отношений с членами ближнего окружения сохраняется в НДМ, но в альтернативном, негативно-деструктивном варианте. Ключевыми признаками домена «Обособление от людей» выступают избегание социальных контактов, замыкание на себе, изоляционизм. Предположительно, сопоставимыми формами и факторами деструкции, описанными в литератуpe, являются следующие: личность не интересуется людьми или отвергает тех, кто относится к ней благожелательно (Schill, 1990), угроза самомнению (Baumeister, 1997), выпадение из социальных связей и социальная изоляция (Twenge et al., 2002).

Домены НДМ и их ключевые признаки сведены в таблицу (см. таблицу 1).

В конечном итоге есть концептуальные основания в пользу метаиндивидуальной модели деструктивности. Она конкретизирует представления о гетерогенности деструкции в терминах ее доменного строения. Метаиндивидуальная модель деструктивности не претендует на универсальность. Вместе с тем она в значительной степени преодолевает разрозненные представления о деструкции. Кроме того, метаиндивидуальная модель деструктивности обеспечивает концептуальные предпосылки (конструктную валидность) для создания нового (многофакторного) инструмента измерения деструкции. 
Таблица 1

Домены НДМ и их ключевые признаки

\begin{tabular}{|c|c|c|c|}
\hline \multicolumn{2}{|c|}{ Домен } & \multirow{2}{*}{$\begin{array}{c}\text { Ключевые } \\
\text { признаки } \\
\text { домена НДМ }\end{array}$} & \multirow{2}{*}{$\begin{array}{c}\text { Предположительно сопоставимые } \\
\text { формы и факторы деструкции, } \\
\text { описанные в литературе }\end{array}$} \\
\hline МИМ & НДМ & & \\
\hline Авторство & $\begin{array}{l}\text { Недовольство } \\
\text { собой }\end{array}$ & $\begin{array}{l}\text { Негативное } \\
\text { самоотношение, } \\
\text { пониженное } \\
\text { самоуважение, } \\
\text { пессимизм }\end{array}$ & $\begin{array}{l}\text { Пониженное самоуважение, желание } \\
\text { принести себе вред и ущерб, неприятие } \\
\text { себя (Baumeister, Scher, 1988), } \\
\text { негативное мнение о себе (Lundh et al., } \\
\text { 2007; Renaud, МcConnell, 2007), } \\
\text { заслуженное самонаказание (Callan et } \\
\text { al., 2014), ментальное поражение, } \\
\text { утрата самоидентичности (Ehlers et al., } \\
\text { 1998, 2000), бессилие (Frederick, 1986; } \\
\text { Негтап, 1992), склонность личности } \\
\text { испытывать неприязнь и быть } \\
\text { придирчивой к себе, бояться успеха и } \\
\text { счастья (Нуler, Rieder, 1987) }\end{array}$ \\
\hline Обладание & $\begin{array}{l}\text { Власть над } \\
\text { людьми }\end{array}$ & $\begin{array}{l}\text { Стремление к } \\
\text { превосходству, } \\
\text { вмешательство, } \\
\text { давление }\end{array}$ & $\begin{array}{l}\text { Оскорбление (Muller et al., 2000; } \\
\text { Taussig, Litrownik, 1997), негативное } \\
\text { лидерство (Krasikova et al., 2013; Reed, } \\
\text { Bullis, 2009), тирания (Ashforth, 1994), } \\
\text { креативность деструктивньх фантазий } \\
\text { (Knauss, 1999; Minocha et al., 2014) }\end{array}$ \\
\hline Принятие & $\begin{array}{l}\text { Неприятие } \\
\text { людей }\end{array}$ & $\begin{array}{l}\text { Категоричность, } \\
\text { повышенная } \\
\text { критичность, } \\
\text { нетерпимость, }\end{array}$ & $\begin{array}{l}\text { Тщеславие, высокомерие, нарциссизм } \\
\text { (Baumeister, 1997; Miller et al., 2009; } \\
\text { Vazire, Funder, 2006) }\end{array}$ \\
\hline Связанность & $\begin{array}{l}\text { Обособление } \\
\text { от людей }\end{array}$ & $\begin{array}{l}\text { Избегание } \\
\text { социальных } \\
\text { контактов, } \\
\text { замыкание на } \\
\text { себе, } \\
\text { изоляционизм }\end{array}$ & $\begin{array}{l}\text { Личность не интересуется людьми или } \\
\text { отвергает тех, кто относится к ней } \\
\text { благожелательно (Schill, 1990), угроза } \\
\text { самомнению (Baumeister, 1997), } \\
\text { выпадение из социальных связей и } \\
\text { социальная изоляция (Twenge et al., } \\
\text { 2002) }\end{array}$ \\
\hline
\end{tabular}

\section{Полярность и континуум миров}

Выше НДМ рассматривался как антипод МИМ по линии деструктивности (негативности) - конструктивности (позитивности), соответственно домены НДМ - как альтернативы доменам МИМ. В этом свете встает вопрос об отношениях НДМ и МИМ: они полярные и/или континуальные?

И полярность, и континуальность

Полярность подразумевает, что НДМ обособляется, существуя 
отдельно от МИМ и параллельно с ним. К полюсу МИМ (и его доменам) стягиваются конструктивность и позитивность в их наиболее выраженной степени, к полюсу НДМ (и его доменам) - деструктивность и негативность в их наиболее выраженной степени. Эти качественные различия «разрешают» рассматривать НДМ как самостоятельную область исследования, абстрагируясь от МИМ. Но из предмета анализа выпадает тогда и даже не предполагается связь НДМ с МИМ. Иначе говоря, полярный взгляд открывает НДМ как самостоятельную область исследования, но в то же время отрывает ее от МИМ. Односторонность (и ограниченность) полярного подхода в том и состоит, что отношения НДМ с МИМ выводятся из поля внимания.

Выше мы писали о том, что НДМ появляется в результате деформации МИМ. Понятие деформации не вписывается в полярный подход, поскольку размывает полярность и вступает в противоречие с ним. Между тем деформация выступает важным звеном, которое оформляется затем в виде НДМ. Под этим углом зрения конструктивной представляется идея континуальности. Она удерживает идею полярности МИМ и НДМ, но идет дальше, подразумеваются градиентные переходы между ними по линии поступенных деформаций МИМ. Их можно отслеживать на уровне переменных, доменов, МИМ в целом.

В конечном итоге НДМ исследуется по двум дополняющим линиям. В соответствии с первой принимаются во внимание деформации МИМ и рассматриваются их постепенные переходы к НДМ. Согласно второй линии, учитывается возникающий при этом НДМ, который (в пределе) противостоит МИМ. Так возникает их полярность.

В плане теоретико-эмпирическом фундаментальным является вопрос поиска маркера континуальных переходов от МИМ без деформаций к МИМ с деформациями и далее к НДМ. Это также вопрос операционализации маркера в определенных аспектах. Во-первых, маркер должен быть континуальным. Без признаков континуальности он утрачивает функцию показателя континуальных перемен от МИМ к НДМ. Во-вторых, ожидается, что показатели континуального маркера ассоииируются c показателями континуальных переходов от МИМ к НДМ. Если маркер является метафорой, он выступает аналогом континуальных переходов от МИМ к НДМ. В-третьих, маркер является внешним и критериальньм по отношению к мирам. При соблюдении этого условия валидность континуальных переходов от МИМ к НДМ в терминах их ассоциаций с маркером объективируется. Критериальность же маркера состоит в том, что по нему можно судить о континуальных переменах от МИМ к НДМ. Наконец, в-четвертых, маркер ожидается простьм, доступным наблюдению и измерениям.

\section{Монохромная метафора}

Можно ли найти маркер, который соответствовал бы обозначенным выше требованиям? Во-первых, обратимся к метафоре как аналогу полярности и континуальных переходов от МИМ к НДМ. 
Как известно, метафора представляет собой осмысление и переживание явлений одного рода в терминах явлений другого рода, обеспечивает частичное понимание одного вида опыта на основе другого вида опыта. Метафора порождается сознанием, а не языком, связь с которым вторична (Лакофф, Джонсон, 2004). Применение научных метафор - обычное дело в психологии и ведет к эвристическим аналогиям. Д. Джентнер и Дж. Грудин (Gentner, Grudin, 1985) насчитали 265 метафор ментальных феноменов и распределили их по четырем категориям: живые организмы, нейрональные, пространственные и системные. Кроме того, были выделены метафоры, укорененные в механике и других разделах физики. Э. Титченер (Titchener, 2005) обрашался к химической метафоре. Особенно популярны метафоры в когнитивной психологии, например, компьютерная метафора (Boden, 2008; Fodor, 1987). На смену ей позже пришла нейронно-сетевая метафора (Martindale, 1991). Метафоры в психологии, заимствованные из других научных дисциплин и опирающиеся на непсихические явления, играют важную роль в оформлении психологических теорий и определении путей эмпирических исследований.

Во-вторых, ограничим область метафор сенсорно-перцептивным уровнем. Именно сенсорно-перцептивная метафора обещает быть наиболее простой, доступной наблюдению и измерениям. Отсюда ожидания закономерных ассоциаций сенсорно-перцептивной метафоры с МИМ и НДМ. На первый взгляд, цветовой тест Люшера или цветовой тест отношений Эткинда и Бажина
(2000) наилучшим образом подходят на роль сенсорно-перцептивной метафоры миров. Вместе с тем они вступают в концептуальное противоречие как с полярностью, так и континуальностью МИМ и НДМ. В своих полярностях конструктивно-позитивные и деструктивно-негативные коннотации являются существенно беднее, но и более обобщенными по отношению к метафоре цветовой палитры, т.е. она является избыточной. Казалось бы, можно использовать категории «теплых» и «холодных» цветов в качестве сенсорно-перцептивной метафоры миров. Но фундаментальная обоснованность противопоставления «теплых» и «холодных» цветов сомнительна. В кросс-культурном аспекте и в плане определения значений категория «цвет» вообще не является универсальной. Различение же человеком светлых (и блестящих) и темных (и тусклых) явлений является универсальным. Светлое тесно связано с белым, а темное - с черным (Вежбицкая, 1996), хотя любой цвет имеет разные степени выраженности светлоты.

Монохромная метафора «белый черный» может быть более релевантным и неизбыточным маркером миров по критерию светлоты (с включением серых оттенков), чем цветовая метафора. «Черный» и «белый» противопоставлены друг другу в терминах физических свойств света и психофизических свойств зрения (Там же). К тому же светлые и темные оттенки серого цвета могут быть развернуты в непрерывную шкалу между белым и черным. В европейской культуре белый цвет (светлый) связан с поло- 
жительными ассоциациями, а черный цвет (темный) многие связывают с негативными ассоциациями. Это монохром, в котором черный и белый оттенки раздваиваются, образуя светлотные полюса цвета, их контраст и дополнительность. В то же время это монохром с градиентными изменениями светлоты на бело-серо-черном континууме.

Предположительно, «белый» («светлый») - это метафора МИМ, а «черный» («темный») - это метафора НДМ. Кроме того, «белый» МИМ может иметь собственные светлотные градации, а «черный» НДМ свои.

Монохромная метафора является знаковой для МИМ и НДМ, поскольку предполагает нечто большее, чем только репрезентацию сознания, экспрессивность языка и речи. Судя по всему, монохромная метафора (прежде всего сенсорноперцептивная) ассоциируется с полярностью и континуальностью миров и может служить их маркером.

Ряд данных косвенно поддерживает эту гипотезу, хотя и применительно к несколько иным явлениям. Так, позитивные оценки перцептивных стимулов воспринимаются более светлыми, чем негативные оценки. Негативные стимулы вызывают более быстрое время реакции, если их черный цвет дан в сравнении с белым цветом. Эти результаты свидетельствуют в пользу аффективной метафоры (Meier et al., 2007). Г. Шерман и Дж. Клор (Sherman, Clore, 2014) указывают на то, что метафора светлоты применима к интеллекту: скажем, «у него светлая голова». Белую и темную сторону относят к креативности. Оригиналь- ных людей называют «белыми воронами», т.е. необычными (Мажуль, Петров, 2010; Petrov, Locher, 2011). У креативности есть и темная сторона (Cropley et al., 2010). В частности, она проявляется в нередких нарушениях креативными людьми норм этики; оригинальные мыслители могут быть непорядочными (Gino, Ariely, 2012). «Темная» метафора употребляется для обозначения некоторых личностных свойств. Психопатия, макиавеллизм и нарциссизм подводятся под обший знаменатель термином «темная триада» (Maples et al., 2014), а макиавеллизм, нарциссизм, психопатия и повседневный садизм - термином «темная тетрада» (Paulhus, 2014). Подобно черным дырам в космосе, травма трактуется как «черная дыра», которая притягивает к себе мысли, память, ассоциации человека, пережившего посттравматический стресс (Pitman, Orr, 1990).

Впрочем, все эти данные свидетельствуют о том, что монохромная метафора, скорее всего, является неспецифической и служит маркером довольно широкого круга явлений. Несмотря на это обстоятельство, монохромную метафору можно использовать для тестирования полярности и континуальности МИМ и НДМ. Метаиндивидуальная модель деструктивности обеспечивает концептуальные предпосылки для создания монохромной шкалы в плане косвенных измерений полярности и континуальности МИМ и НДМ.

\section{Заключение}

Попытка построить метаиндивидуальную модель деструктивности 
привела к следующим результатам. С позиций концепции МИМ вводится понятие НДМ у психически здоровых людей. Анализ НДМ проводился по нескольким линиям: как деформация МИМ, доменная специфика НДМ, полярность и континуальность МИМ и НДМ.

Деформации могут затрагивать домены, отдельные системы, МИМ в целом. Предельный случай - появление НДМ. Его домены выявляются как негативно-деструктивные альтернативы доменов МИМ: недовольство собой в оппозиции к авторству, стремление к власти над людьми в оппозиции к психологическому обладанию, неприятие людей в оппозиции к их приятию, обособление от людей в оппозиции к связанности с ними. Доменная организация НДМ позволила конкретизировать представления о гетерогенных источниках и формах деструкции.

Отношения НДМ и МИМ рассматривались как полярные и континуальные. Континуальными являются постепенные переходы от МИМ без деформаций к МИМ с деформациями, а затем к НДМ. МИМ и НДМ образуют полюса континуальных переходов между ними.

Специальное внимание обрашалось на маркер континуальных пере- ходов от МИМ к НДМ. Были сформулированы операциональные требования к маркеру: континуальность, ассоциации с показателями континуальных переходов от МИМ к НДМ, внешний и критериальный характер по отношению к мирам, простота, доступность для наблюдений и измерений. В свете этих требований, был поставлен вопрос о том, что маркер континуальных переходов между МИМ и НДМ может рассматриваться как метафора. Предлагалось область ее применения ограничить сенсорно-перцептивным уровнем. Был выбран бело-черный монохром (по светлоте) как метафора (аналог) миров. «Белый» («светлый») - это метафора МИМ, «черный» («темный») - метафора НДМ. Предположительно монохромная метафора служит маркером и полярности, и континуальности МИМ и НДМ.

Развитие метаиндивидуальной модели деструктивности в эмпирической плоскости предполагает в качестве следуюшей и ближайшей задачи создание релевантных инструментов измерения, в первую очередь многофакторного вопросника негативной деструктивности и монохромной шкалы применительно к МИМ и НДМ.

\section{Литература}

Вежбицкая, А. (1996). Язык. Культура. Позиание. М.: Русские словари.

Дорфман, Л. Я. (2007). Метаиндивидуальная и полимодальная модели креативности. В кн. В. М. Петров, А. В. Харуто (ред.), Информация, время, твориество (с. 73-79). М.: Государственный институт искусствознания / Московская государственная консерватория им. П.И. Чайковского.

Дорфман, Л. Я. (2016). Каузальный плюрализм и холизм в концепции метаиндивидуального мира. Психология. Журнал Высшей иколы экономики, 13(1), 98-136. 
Дорфман, Л. Я., Злоказов, К. В. (2016). Поражение и деструкция и их исследование в зарубежной психологии. Сообщение 2. Вестник Южно-Уральского государственного университета. Серия: Психология, 9(2), 5-13.

Дорфман, Л. Я., Злоказов, К. В. (2017). Метаиндивидуальная модель деструктивности. Сообщение 1. Психология. Журиал Высшей иколь экономики, 14(10), 105-122.

Дорфман, Л. Я., Зубакин, М. В. (2008). Новые данные об эмпирических референтах областей метаиндивидуального мира. В кн. Б. А. Вяткин (ред.), ХХІІІ Мерлинские чтения: «Активность - индивидуальность - субъект» (с. 35-37). Пермь: Пермский государственный педагогический университет.

Дорфман, Л. Я., Лядов, В. Н. (2015). Метаиндивидуальная модель дисциплинированности (на материале исследования курсантов военного вуза МВД). Вестник Южн-Уральского государственного университета. Серия: Психология, 8(1), 17-28.

Лакофф, Дж., Джонсон, М. (2004). Метафоры, которыми мы живем. М.: Едиториал УРСС.

Мажуль, Л. А., Петров, В. М. (2010). Оригинальность творчества: феномен «rara avis» в живописи (Опыт количественного анализа). В кн. Л. Я. Дорфман, Д. В. Ушаков (ред.), Психология творчества: наследие Я. А. Пономарева и современные исследования (с. 297-300). Пермь/М.: Пермский государственный институт искусства и культуры/Институт психологии РАН.

Петровский, В. А. (1981). К пониманию личности в психологии. Вопросы психологии, 2, 40-46.

Петровский, В. А. (1997). Очерк теории свободной причинности. В кн. Д. А. Леонтьев, В. Г. Щур (ред.), Психология с человеческим лицом: гуманистическая перспектива в постсоветской психологии (с. 124-144). М.: Смысл.

Петровский, В. А. (2009). Логика «Я»: персонологиеская перспектива. Самара: Изд-во САМГУ. Петровский, В. А. (2013). «Я» в персонологической перспективе. М.: Издательский дом НИУ ВШЭ.

Петровский, В. А., Старовойтенко, Е. Б. (2012). Наука личности: четыре проекта общей персонологии. Психология. Журиал Высшей иколы экономики, 9(1), 2139.

Сыманюк, Э. Э. (2005). Психологиеские основания профессиональных деструкций педагога (Докторская диссертация, Российский государственный профессионально-педагогический университет, Екатеринбург).

Эткинд, А. М., Бажин, Е. Ф. (2000). Цветовой тест отношений. СПб.: Иматон.

Ссылки на зарубежные источники см. в разделе References после анголяыного блока.

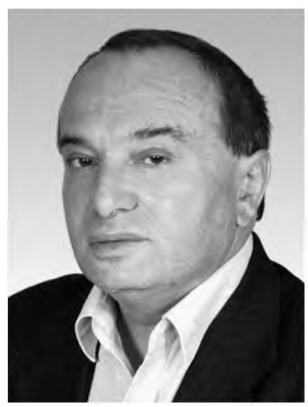

Дорфман Леонид Яковлевич - заведующий кафедрой, кафедра психологии и педагогики, Пермский государственный институт культуры, доктор психологических наук, профессор.

Сфера научных интересов: индивидуальность, деструктивность, креативность.

Контакты: dorfman07@yandex.ru 


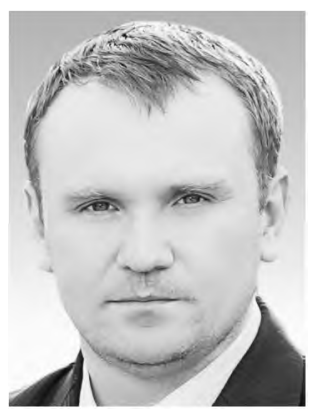

Злоказов Кирилл Витальевич - начальник, кафедра психологии служебной деятельности и педагогики, Уральский юридический институт, кандидат психологических наук, доцент.

Сфера научных интересов: личность, деструктивное поведение, криминальная идентичность.

Контакты: zkrivit@yandex.ru

\title{
A Meta-Individual Model of Destructive Patterns. Report 2
}

\author{
Leonid Ya. Dorfman ${ }^{\mathrm{a}}$, Kyrill V. Zlokazov
}

${ }^{a}$ Perm State Institute of Culture, 18 Gazeta Zvezda Str., Perm, 614000, Russian Federation

${ }^{a}$ Ural Institute of Law, 21 Korepina Str., Ekaterinburg, 620017, Russian Federarion

\begin{abstract}
The meta-individual model of destructivity has been proposed. It is intended to present a common view on destructivity and to overcome the hampering effects of fragmentation of destructivity that still dominates psychology. Isolated views on destructive patterns exist due to their partition among trauma, depression, aggression, violence, abuse, and the like. The question of how a composition of destructive patterns appears is still unanswered. This matter is salient but least understandable from the integrative and systems viewpoint. The meta-individual model of destructivity solves the problem because it conceptualizes fragmented parts of destructive patterns, describing them as a unified phenomenon in an integrative fashion. The notion of negativedestructive world of mentally healthy people has been introduced. It arises as a result of the meta-individual world suffering from distortion either as a whole or across its systems and domains. Our claim is that 4 domains of the negative-destructive world should be specified as opposed to respective domains of the meta-individual world. They are following: self-displeasure vs. agency, power over others vs. psychological possession, rejection of people vs. perspectivetaking, detachment from people vs. relatedness to them. Presumably, the domain organization of the negative-destructive world entails heterogeneity of destructivity. Besides, a monochrome metaphor "white" ("light") - "black" ("dark") has been suggested as a sensorial-perceptual marker of the meta-individual world ("light") and the negative-destructive world ("dark"), as well as their polarities and continuous transitions. To secure the empirical research on the meta-individual model of destructivity, a respective multidimensional questionnaire, as well as a monochrome scale are required to be created.
\end{abstract}

Keywords: destruction, meta-individual model, distortion, negative-destructive world, domains, monochrome metaphor. 


\section{References}

Ashforth, B. E. (1994). Petty tyranny in organizations. Human Relations, 47, 755-778. doi:10.1177/001872679404700701

Baumeister, R. F. (1990). Suicide as escape from self. Psychological Review, 97, 90-113. doi:10.1037/0033-295X.97.1.90

Baumeister, R. F. (1997). Esteem threat, self-regulatory breakdown, and emotional distress as factors in self-defeating behavior. Review of General Psychology, 1(2), 145-174. doi:10.1037/10892680.1.2.145

Baumeister, R. F., \& Scher, S. J. (1988). Self-defeating behavior patterns among normal individuals: Review and analysis of common self-destructive tendencies. Psychological Bulletin, 104(1), 3-22. doi:10.1037/0033-2909.104.1.3

Blatt, S. J. (2008). Polarities of experience: Relatedness and self-definition in personality development, psychopathology, and the therapeutic process. Washington, DC: American Psychological Association.

Boden, A. (2008). Mind as machine: A history of cognitive science. Oxford: Oxford University Press.

Callan, M. J., Kay, A. C., \& Dawtry, R. J. (2014). Making sense of misfortune: Deservingness, selfesteem, and patterns of self-defeat.Joumal of Personality and Social Psychology, 107(1), 142-162. doi: $10.1037 / \mathrm{a} 0036640$

Cropley, D., Kaufman, J., Cropley, A., \& Runco, M. (Eds.). (2010). The dark side of creativity. New York: Cambridge University Press.

Dorfman, L. Ya. (2007). Metaindividual'naya i polimodal'naya modeli kreativnosti [Meta-individual and polymodal models of creativity]. In V. M. Petrov \& A. V. Kharuto (Eds.), Informatsiya, vremya, tworchestzo [Information, time, creativity] (pp. 73-79). Moscow: Gosudarstvennyi institut iskusstvoznaniya / Moscow Conservatory.

Dorfman, L. Ya. (2016). The causal pluralism and holism in the meta-individual world theory. Psychology. Journal of Higher School of Economics, 13(1), 115-153. (in Russian)

Dorfman, L., \& Barashkova, E. (2016). A meta-individual perspective in personality studies. Australian Joumal of Education and Science, 1(17), 304-313.

Dorfman, L. Ya., \& Liadov, V. N. (2015). The meta-individual model of discipline (based on cadets at the military university of the Russian Internal Troops). Bulletin of the South Ural State University. Series Psychology, 8(1), 17-28. (in Russian)

Dorfman, L. Ya., \& Zlokazov, K. V. (2016). Defeat and destructive patterns: a brief review of recent studies. Part 2. Bulletin of the South Ural State University. Series Psychology, 9(2), 5-13. (in Russian)

Dorfman, L. Ya., \& Zlokazov, K. V. (2017). A meta-individual model of destructive patterns. Report 1. Psychology. Joumal of Higher School of Economics, 14(1), 105-122. (in Russian)

Dorfman, L. Ya., Zubakin, M. V. (2008). Novye dannye ob empiricheskikh referentakh oblastei metaindividual'nogo mira [New data on empirical referents of the realms of meta-individual world]. In B. A. Vyatkin (Ed.), XXIII Merlinskie chteniya: "Aktivmost' - individual'nost' - sub"ekt" [Merlin's readings: "Activity - individuality - subject"] (pp. 35-37). Perm: Perm State Pedagogical University.

Dorfman, L., \& Ogorodnikova, A. (2007). Plural self, plural achievement motives, and creative thinking. In L. Dorfman, C. Martindale, \& V. Petrov (Eds.), Aesthetics and innovation (pp. 125-160). Cambridge: Cambridge Scholars Press.

Echterhoff, G. E., Higgins, T., \& Levine, J. M. (2009). Shared reality: Experiencing commonality with others' inner states about the world. Perspectives on Psychological Science, 4(5), 496-521. doi:10.1111/j.1745-6924.2009.01161.x 
Ehlers, A., Maercker, A., \& Boos, A. (2000). Post-traumatic stress disorder following political imprisonment: The role of mental defeat, alienation, and perceived permanent change. Joumal of Abnormal Psychology, 109, 45-55. doi:10.1037/0021-843X.109.1.45

Ehlers, A., Clark, D. M., Dunmore, E. B., Jaycox, L., Meadows, E., \& Foa, E. B. (1998). Predicting the response to exposure treatment in PTSD: The role of mental defeat and alienation. Joumal of Traumatic Stress, 11, 457-471. doi:10.1023/A:1024448511504

Etkind, A. M., \& Bazhin, E. F. (2000). Tsvetovoi test otnoshenii [The Colored Test of Attitudes]. Saint Petersburg: Imaton.

Fodor, J. A. (1987). Psychosemantics: The problem of meaning in the philosophy of mind. Cambridge, MA: MIT Press.

Frederick, C. J. (1986). Psychic trauma in victims of crime and terrorism. In G. R. VandenBos \& B. K. Bryant (Eds.), Cataclysms, crises, and catastrophes: Psychology in action (pp. 55-108). Washington, DC: American Psychological Association. doi:10.1037/11106-002

Gentner, D., \& Grudin, J. (1985). The evolution of mental metaphors in psychology: A 90-year retrospective. American Psychologist, 40(2), 181-192. doi:10.1037/0003-066X.40.2.181

Gino, F., \& Ariely, D. (2012). The dark side of creativity: Original thinkers can be more dishonest. Joumal of Personality and Social Psychology, 102(3), 445-459. doi:10.1037/a0026406

Herman, J. L. (1992). Complex PTSD: A syndrome in survivors of prolonged and repeated trauma. Joumal of Traumatic Stress, 5, 377-391. doi:10.1002/jts.2490050305

Hyler, S. E., \& Rieder, R. R. (1987). PDQ-R: Personality Diagnostic Questionnaire-Revised. New York: New York State Psychiatric Institute.

Knauss, W. (1999). The creativity of destructive fantasies. Group Analysis, 32, 397-411. doi:10.1177/05333169922076914

Krasikova, D. V., Green, S. G., \& LeBreton, J. M. (2013). Destructive leadership: A theoretical review, integration, and future research agenda. Journal of Management, 39(5), 1308-1338. doi: $10.1177 / 0149206312471388$

Lakoff, G., \& Johnson, M. (2004). Metafory, kotonymi my zhivem [Metaphors we live by]. Moscow: Editorial URSS. (Transl. of: Lakoff, G., \& Johnson, M. (1980). Metaphors we live by. Chicago/London: University of Chicago Press).

Lundh, L., Karim, J., \& Quilish, E. (2007). Deliberate self-harm in 15-year-old adolescents: A pilot study with a modified version of the deliberate self-harm inventory. Scandinavian Joumal of Psychology, 48, 33-41. doi:10.1111/j.1467-9450.2006.00567.x

Maples, J. L., Lamkin, J., \& Miller, J. D. (2014). A test of two brief measures of the dark triad: The dirty dozen and short dark triad. Psychological Assessment, 26(1), 326-331. doi:10.1037/a0035084

Martindale, C. (1991). Cognitive psychology: A neural-network approach. Pacific Grove, CA: Brooks/Cole.

Mazhul, L. A., \& Petrov, V. M. (2010). Original'nost' tvorchestva: fenomen "rara avis" v zhivopisi (Opyt kolichestvennogo analiza) [Originality of creativity: a phenomenon of "rara avis" in painting]. In L. Ya. Dorfman \& D. V. Ushakov (Eds.), Psikhologiya tvorchestva: nasledie Ya. A. Ponomareva i sovremennye issledovaniya [The psychology of creativity: the heritage of Ya. A. Ponomarev and contemporary research] (pp. 297-300). Perm/Moscow: Permskii gosudarstvennyi institut iskusstva i kul'tury/Institute of Psychology of Russian Academy of Sciences.

Meier, B. P., Robinson, M. D., Crawford, L. E., \& Ahlvers, W. J. (2007). When "light" and "dark" thoughts become light and dark responses: Affect biases brightness judgments. Emotion, 7(2), 366376. doi:10.1037/1528-3542.7.2.366 
Miller, J. D., Campbell, W. K., Young, D. L., Lakey, C. E., Reidy, D. E., Zeichner, A., \& Goodie, A. S. (2009). Examining the relations among narcissism, impulsivity, and self-defeating behaviors. Joumal of Personality, 77, 761-794. doi:10.1111/j.1467-6494.2009.00564.x

Minocha, S., Stonehouse, G., \& Reynolds, M. (2014). Bollywood on creativity: An interview with the internationally acclaimed film director Shekhar Kapur. Joumal of Management Inquiry, 23(2), 137-147. doi:10.1177/105649261349982

Muller, R. T., Sicoli, L. A., \& Lemieux, K. E. (2000). Relationship between attachment style and posttraumatic stress symptomatology among adults who report the experience of childhood abuse. Journal of Traumatic Stress, 13, 321-332. doi:10.1023/A:1007752719557

Paulhus, D. L. (2014). Toward a taxonomy of dark personalities. Current Directions in Psychological Science, 23(6), 421-426. doi:10.1177/0963721414547737

Petrov, V. M., \& Locher, P. J. (2011). Genius: A son of his time or a Rara Avis? Empirical Studies of the Arts, 29, 111-128. doi:10.2190/EM.29.1.g

Petrovsky, V. A. (1981). K ponimaniyu lichnosti v psikhologii [On the understanding of personality in psychology]. Voprosy Psikhologii, 2, 40-46.

Petrovsky, V. A. (1997). Ocherk teorii svobodnoi prichinnosti [An essay on the theory of free causality]. In D. A. Leontiev \& V. G. Shchur (Eds.), Psikhologiya s chelovecheskim litsom: gumanisticheskaya perspektiva v postsovetskoi psikhologii [Psychology with a human face: humanistic perspective in post-soviet psychology] (pp. 124-144). Moscow: Smysl.

Petrovsky, V. A. (2009). Logika "Ya": personologicheskaya perspektiva [The logic of the Self: a personological perspective]. Samara: Samara State University.

Petrovsky, V. A. (2013). "Ya" v personologicheskoi perspektive [The Self in a personological perspective]. Moscow: HSE Publishing House.

Petrovsky, V. A., \& Starovoytenko, E. B. (2012). The science of personality: Four projects of general personology. Psychology. Joumal of Higher School of Economics, 9(1), 21-39. (in Russian)

Pierce, J. L., Kostova, T., \& Dirks, K. T. (2003). The state of psychological ownership: Integrating and extending a century of research. Review of General Psychology, 7(1), 84-107. doi:10.1037/10892680.7.1.84

Pitman, R. K., \& Orr, S. (1990). The black hole of trauma. Biological Psychiatry, 27, 469-471. doi:10.1016/0006-3223(90)90437-7

Reed, G. E., \& Bullis, R. C. (2009).The impact of destructive leadership on senior military officers and civilian employees. Armed Forces and Society, 36(1), 5-18. doi:10.1177/0149206312471388

Renaud, J. M., \& McConnell, A. R. (2007). Wanting to be better but thinking you can't: Implicit theories of personality moderate the impact of self-discrepancies on self-esteem. Self and Identity, 6 , 41-50. doi:10.1080/15298860600764597

Schill, T. (1990). A measure of self-defeating personality. Psychological Reports, 66, 1343-1346. doi:10.2466/pr0.1990.66.3c.1343

Sherman, G. D., \& Clore, G. L. (2014). Do evaluative metaphors shape emotional thought? A call for new evidence. In M. Landau, M. D. Robinson, \& B. P. Meier (Eds.), The power of metaphor: Examining its influence on social life (pp. 205-223). Washington, DC: American Psychological Association. doi:10.1037/14278-013

Symanyuk, E. E. (2005). Psikhologicheskie osnovaniya professional'nykh destruktsii pedagoga [The psychological grounds of professional destructivity of a teacher] (Doctoral dissertation, Russian State Vocational Pedagogical University, Yekaterinburg, Russian Federation). 
Taussig, H. N., \& Litrownik, A. J. (1997). Self- and Other-directed destructive behaviors: Assessment and relationship to type of abuse. Child maltreatment, 2(2), 172-182. doi:10.1177/ 1077559597002002010

Thoroughgood, C. N., Tate, B. W., Sawyer, K. B., \& Jacobs, R. (2012). Bad to the bone: Empirically defining and measuring destructive leader behavior. Joumal of Leadership and Organizational Studies, 19(2), 230-255. doi:10.1177/1548051811436327

Titchener, E. (2005). A beginner's psychology. Boston, MA: Adamant Media Corporation.

Twenge, J. M., Catanese, K. R., \& Baumeister, R. F. (2002). Social exclusion causes self-defeating behavior. Joumal of Personality and Social Psychology, 83(3), 606-615. doi:10.1037/00223514.83.3.606

Vazire, S., \& Funder, D. C. (2006). Impulsivity and the self-defeating behavior of narcissists. Personality and Social Psychology Reviere, 10, 154-165. doi:10.1207/s15327957pspr1002_4

Vezhbitskaya, A. (1996). Yazyk. Kultura. Poznanie [Language. Culture. Cognition]. Moscow: Russkie slovari.

Leonid Ya. Dorfman - head of Psychology and Pedagogy chair, Perm State Institute of Culture, D.Sc.

E-mail: dorfman07@yandex.ru

Kyrill V. Zlokazov - head of Psychology of activity special field and Pedagogy chair, Ural Institute of Law, Ph.D.

E-mail: zkirvit@yandex.ru 